\title{
Future of People Analytics: The Case of Petroleum Development Oman
}

\author{
Zahra Bait Ishaq \\ Dr. Maria Teresa Matriano
}

\author{
MIDDLE EAST COLLEGE \\ Middle East College
}

\begin{abstract}
High employee turnover rate has been a major issue facing many organizations in the world. This research aims to discover the effect of people analytics on employee turnover rates as well as the employee's performance on the job. This study contains a systemic review of articles and papers on people analytics. Analytics has been taking a major factor in the everyday business operations whether that be in predicting consumer behavior in order to drive sales or to support theories by identifying patterns in the data. Therefore, it is vital for companies to capture, understand and analyze data to be able to stay competitive in the market. Big oil and gas companies focus on employee's wellbeing and employees job satisfaction because they realize just how important employees are in the company and the role they play in operation excellence. In the case of PDO, this company depends solely on employees rather than consumers to cover the costs of operations hence, it is noticed that there is a higher emphasis on the employees and their wellbeing more than any other company. This paper focuses on the importance of people analytics in organizations and how analytics can help lower employee turnover rates and drive performance.
\end{abstract}

\section{Introduction}

Oman's petroleum industry is still the country's major economic driver with an estimated contribution of 37.1\% towards GDP in 2018 (Times News Service 2019). Activities in the petroleum industry is still seeing a significant growth combined with relevant improvement in business performance. Part of the long-term plan is establishing worker metrics that includes human resource, worker welfare, values, health and safety, and training and development. The goal of the plan for gathering data through the aforementioned metrics; is to create a long-term delivery of large-scale diagnostic survey of the industry's key worker metrics, relative to finding gaps in the current human resource practices (IDG 2019).

The future of people analytics in Oman's petroleum industry relies on the amount of data gathered from the large-scale diagnostic survey of the industry's key worker metrics. Profound technological advances paired with analytical tools to reimagine how work gets done, where worker welfare is critical, and finding more effective process solutions (Hagen et al. 2017). The key components of people analytics in Oman is the use of big data to predict the outcomes in decision making and finding more effective retention initiatives. One of the best examples of future improvement in people analytics in Oman is the deployment of industrial mobility tools that will aid in boosting worker safety. One of the leading global petroleum brand Shell, leads the initiative of improving worker safety in Oman through mobility tools (World Economic Forum 2017).

The important role of mobility tools is to enable fieldworkers to have access to the right information at any given time and are properly trained to use the mobility tools. Shell's organizational initiative to deploy mobility tools was a result of the long-term people analytics plan in collaboration with Petroleum Development Oman (World Economic Forum 2017). The collaboration also resulted to the creation of an ecosystem in which industrial mobility platform that made fieldworkers $20 \%$ more efficient (World Economic Forum 2017). The use of HR analytics in Oman's petroleum industry is becoming increasingly important for decisions involving worker promotion, workforce design, performance management, and development of data-driven HR strategies (CIPD 2015). 
Future plans for greater integration of people analytics in Oman's petroleum industry also includes improving human resource planning in the public sector particularly in education (Al Wahsh 2016). The role of education and the public sector in particular is to establish the fundamental knowledge in analyzing big data and application of technological tools that are essential to people science. Most of the efforts for the future of people analytics involves the circular collaborative ecosystem in which various digital platforms were developed collaboration within the petroleum ecosystem (World Economic Forum, 2017). The role of digital platforms in the future of people analytics is to create information-sharing across the industry. The digital platform will link communities of interest and stakeholders in creating mutually beneficial projects aimed to improve workers' welfare

\section{Future of people analytics in Oman}

In the last decade, the oil industry has seen a significant change in resource availability particularly in terms of technical talent resource. The observed resource scarcity has contributed to the higher global oil prices. In addition, globalization have also impacted the creation of centralized technical capabilities that could enable the oil industry to deploy scarce talents in its core function areas. One of the important technological advances that could potentially disrupt the old ways of utilizing human resource in the oil industry, and significantly address the issue of talent scarcity is the use people analytics. In the case of Oman, people analytics encompasses a significant role in combining data with advanced analytical tools to enable its petroleum industry to reimagine where and how work is done.

People analytics suggests that continuous innovation should encompass enhanced collaboration between organizations in the petroleum industry to create a more efficient workforce management. The future of people analytics in Oman can be observed on the partnership between the private sector and the government to create a collaborative ecosystem. These collaborations are aided by big data and digital platforms with the objective creating solutions for better workers' welfare, reducing cost of human resource, addressing talent acquisition challenges, and improving operations transparency.

\section{The uses of data analytics}

The use of data analytics is more adapted in the areas of marketing because they can predict who and when will a customer buy a product and how different marketing strategies effect the drive of sales therefore, outcomes are very easily and conveniently measured even often collected automatically through the sales process and observations over time (Cappelli, Tambe and Yakubovich 2018) Similarly, van der Togt and Rasmussen 2017 discusses in their journal article Toward evidence-based HR the ever-increasing amount of data promote data mining and empty empiricism and access to available facts simultaneously generates $80 \%$ of the value without complex analytics because it enables fact-based assessment and decisions.

According to Lal 2015 in her journal transforming HR in the digital era there are five key aspects where employee analytics can be mostly useful and they are: Workforce planning, the management and improvement of business performance, learning and development, retention and finally, compensation correspondingly, in Harris, Craig and Light 2011 journal they explain how analytics can be used to systematically and rigorously identify critical talent such as identifying top performers and how an analytical approach to recruiting, training and maintain the people who work for an organization can help them discover the employees that generate the greatest performance and use that knowledge to focus on their talent investments. Likewise, in Buck and Morrow 2018 journal they explain about the importance of understanding without bias, who within the company are the best performers and who have the potential to be a leader and prioritize their retention 


\section{Journal of Student Research}

Fourth Middle East College Student Research Conference, Muscat, Sultanate of Oman

Currently, Oman's petroleum industry is focusing its resources towards investments to enhance oil recovery (Al-Riyami N.D.). Despite the current strategies conceptualized to enhance human resource development with the use of people analytics, there is still a need to look in the future of workforce in through big data and digitalization. The current dimensions of human resource development in Oman includes achieving balance between economic growth and population (AlRiyami N.D.). Achieving successful future of people analytics in Oman's petroleum industry is to examine local policies for possible interventions (OOGC N.D.).

The future of people analytics can be summarized into a few collaborations between petroleum companies operating in Oman. One example of such collaboration to bring people analytics into the petroleum industry is creating a circular collaboration environment in which information-sharing is enabled by digital platforms and big data. Current strategies in creating a collaborative environment for the future of people analytics in Oman includes creating metrics that will measure workers' welfare, which would be an important basis for the future of people analytics in the country.

\section{Conclusion}

In conclusion, this study aims to understand the impact of people analytics in employee turnover rate and organization performance and whether it has a positive or negative impact.

When analyzing historical and current data, it can be said that the impact of people analytics on organization performance is positive and the employee turnover rate decreases the more the company focuses on people analytics.

\section{Acknowledgements}

We would like to express our sincere gratitude to everyone that has contributed in the writing of this research.

\section{References}

1. Al Wahsh, A. (2016). Human resource planning practices in the Omani Public Sector: An exploratory study in the Ministry of Education in the Sultanate of Oman. Doctorates and Masters. Edith Cowan University

2. Al-Riyami, A. (n.d.). Oman's Oil \& GAS Industry.

3. Buck, B. and Morrow, J. (2018). AI, performance management and engagement: keeping your best their best. Strategic HR Review, 17(5), pp.261-262

4. Cappelli, P., Tambe, P. and Yakubovich, V. (2018). Artificial Intelligence in Human Resources Management: Challenges and a Path Forward. SSRN Electronic Journal. [online] Available at:https://www.researchgate.net/publication/328798021_Artificial_Intelligence_i n_Human_Resources_Management_Challenges_and_a_Path_Forward [Accessed 24 Nov. 2019]

5. CIDG (2015). Evolution of HR analytics: A Middle East perspective. Research report. [online] Available at: https://www.cipd.asia/Images/evolution-of-hr-analytics-a-middle-eastperspective tcm23-22426.pdf [Accessed 28 Nov. 2019]

6. DeFranzo, S. (2011). Difference between qualitative and quantitative research. [online] Snap Surveys Blog. Available at: https://www.snapsurveys.com/blog/qualitative-vsquantitative-research/ [Accessed 24 Nov. 2019]

7. Easwaramoorthy, M. and Zarinpoush, F. (2006). Interviewing for Research. Canada Volunteerism Initiative.

8. Hagen, T., Pollner, F., Tryggestad, C. and Woxholth, J. (2019). The future of HR in oil and 


\section{Journal of Student Research}

Fourth Middle East College Student Research Conference, Muscat, Sultanate of Oman

gas. [online] McKinsey \& Company. Available at: https://www.mckinsey.com/industries/oiland-gas/our-insights/the-future-of-hr-in-oil-and-gas [Accessed 28 Nov. 2019]

9. Harris, J., Craig, E. and Light, D. (2011). Talent and analytics: new approaches, higher ROI. Journal of Business Strategy, 32(6), pp.4-13

10. IDG (2019). People Analytics: Improving the Welfare of Workers in the Oil \& Gas Industry in Oman - inspirationaldevelopment.com. [online] inspirationaldevelopment.com. Available at: https://www.inspirationaldevelopment.com/people-analytics-improv

11. Lal, P. (2015). Transforming HR in the digital era. Human Resource Management International Digest, 23(3), pp.1-4

12. van der Togt, J. and Rasmussen, T. (2017). Toward evidence-based HR. Journal of Organizational Effectiveness: People and Performance, 4(2), pp.127-132 